\title{
Biophysical Screening of a Focused Library for the Discovery of CYP121 Inhibitors as Novel Antimycobacterials
}

\author{
Christian Brengel ${ }^{+,[a]}$, Andreas Thomann ${ }^{+,[a]}$, Alexander Schifrin ${ }^{[b]}$, Giuseppe Allegretta ${ }^{[a]}$, Ahmed A. M. \\ $\mathrm{Kamal}^{\left[{ }^{[a]}\right.}$, Jörg Haupenthal ${ }^{[a]}$, Isabell Schnorr ${ }^{[a]}$, Sang Hyun Cho ${ }^{[c]}$, Scott G. Franzblau ${ }^{[c]}$, Martin \\ Empting $^{[a]}$, Jens Eberhard ${ }^{[a]}$ and Rolf W. Hartmann ${ }^{*,[a],[d]}$
}

[a] Dr. C. Brengel, Dr. A. Thomann, Dr. G. Allegretta, A. A. M. Kamal, Dr. J. Haupenthal, I. Schnorr, Dr. M. Empting, Dr. J. Eberhard, Prof. Dr. R. W. Hartmann Helmholtz Institute for Pharmaceutical Research Saarland (HIPS)

Department for Drug Design and Optimization

Campus E8.1, 66123 Saarbruecken (Germany)

E-mail: rolf.hartmann@helmholtz-hzi.de

[b] Dr. A. Schifrin

Department of Biochemistry

Saarland University

Campus B2.2, 66123 Saarbruecken (Germany)

[c] Dr. S. H. Cho, Prof. Dr. S. G. Franzblau

Institute for Tuberculosis Research

College of Pharmacy, University of Illinois at Chicago

833 S. Wood St., Chicago, Illinois 60612-7231 (USA)

[d] Prof. Dr. R. W. Hartmann

Department of Pharmacy, Pharmaceutical and Medicinal Chemistry,

Saarland University

Campus C2.3, 66123 Saarbruecken (Germany)

[+] These authors contributed equally to this work.

Supporting information for this article is given via a link at the end of the document.

\begin{abstract}
The development of novel antimycobacterial agents against Mycobacterium tuberculosis (Mtb) is urgently required due to the appearance of multi-drug resistance (MDR) combined with a complicated long-term treatment. CYP121 was shown to be a promising novel target for inhibition of mycobacterial growth. In this study, we describe the rational discovery of new CYP121 inhibitors by a systematic screening based on biophysical and microbiological methods. Best hits originating from only one structural class gave first information about molecular motifs required for binding and activity. The initial screening procedure was followed by mode of action studies and further biological characterizations. The results demonstrate a superior antimycobacterial efficacy and a reduced toxicity profile of our frontrunner compound compared to the reference econazole. Due to its low molecular weight, promising biological profile and physicochemical properties this compound displays an excellent starting point for further rational optimization.
\end{abstract}

\section{Introduction}

Tuberculosis belongs to the most lethal infectious diseases caused by bacteria. According to the WHO Global Tuberculosis Report, ${ }^{[1]} 1.5$ million people died in 2013 due to infections caused by Mtb. This goes along with an estimated amount of 9 million new cases of Mtb infections arising each year. Despite a broad spectrum of first and second line antimycobacterial drugs, there is an antibiotic gap for the treatment of infections with multi-drug-resistant (MDR) and extensively-drug-resistant (XDR) Mtb. ${ }^{[1]}$ Additionally, alarming reports have been published describing totally-drug-resistant Mtb (TDR-TB). ${ }^{[2,3]}$ Moreover, tuberculosis still requires long-term treatment leading to an increased probability for non-compliance which impairs the therapeutic outcome.$^{[4]}$ Hence, there is an urgent need for new antimycobacterial agents with novel modes of action which in best case could also lead to shorter treatment periods.

Driven by the elucidation of the Mtb genome in 1998, ${ }^{[5]}$ new potential drug targets were identified. ${ }^{[6]}$ Interestingly, Mtb exhibits an unusual high number of twenty P450 enzymes in contrast to other bacteria. Further studies have revealed some of them to be essential for viability, survival and/or pathogenicity. ${ }^{[7]}$ Out of these, CYP121 was shown to be essential for bacterial growth by an in vitro knock out study. ${ }^{[8]}$ Moreover, the deficient strain could be revived by a complementary plasmid. ${ }^{[8,9]}$ The first evidence of CYP121 function in Mtb was derived from its gene position which is located in an operon harboring two enzymes involved in the formation of cyclo-di---tyrosine (CYY). ${ }^{[10]}$ In vitro studies provided proof, that CYP121 catalyzes the reaction of cYY to mycocyclosin with high substrate specificity. ${ }^{[10,11]}$ The role of its substrate and product in the cellular setting remains to be elucidated. However, the variety of biological functions of diketopiperazines is well described e.g. as quorum sensing signals. ${ }^{[12]}$ Thus, besides development of antimycobacterials targeting CYP121, a small selective molecule with in cellulo efficiency may help to understand the precise function of CYP121.

Due to the fact that CYP121 is a potential target for Mtb treatment some efforts have been undertaken to identify potent inhibitors. Hudson et al. and Kavanagh et al. published several compounds designed for selective CYP121 binding and inhibition. However, none of them were shown to be effective against Mtb. ${ }^{[13,14]}$ Fonvielle et al. described a CYP121 inhibitory effect of cYY derivatives without data on bacterial growth. ${ }^{[11,15]}$ Kavanagh et al. designed compounds based on substrate 

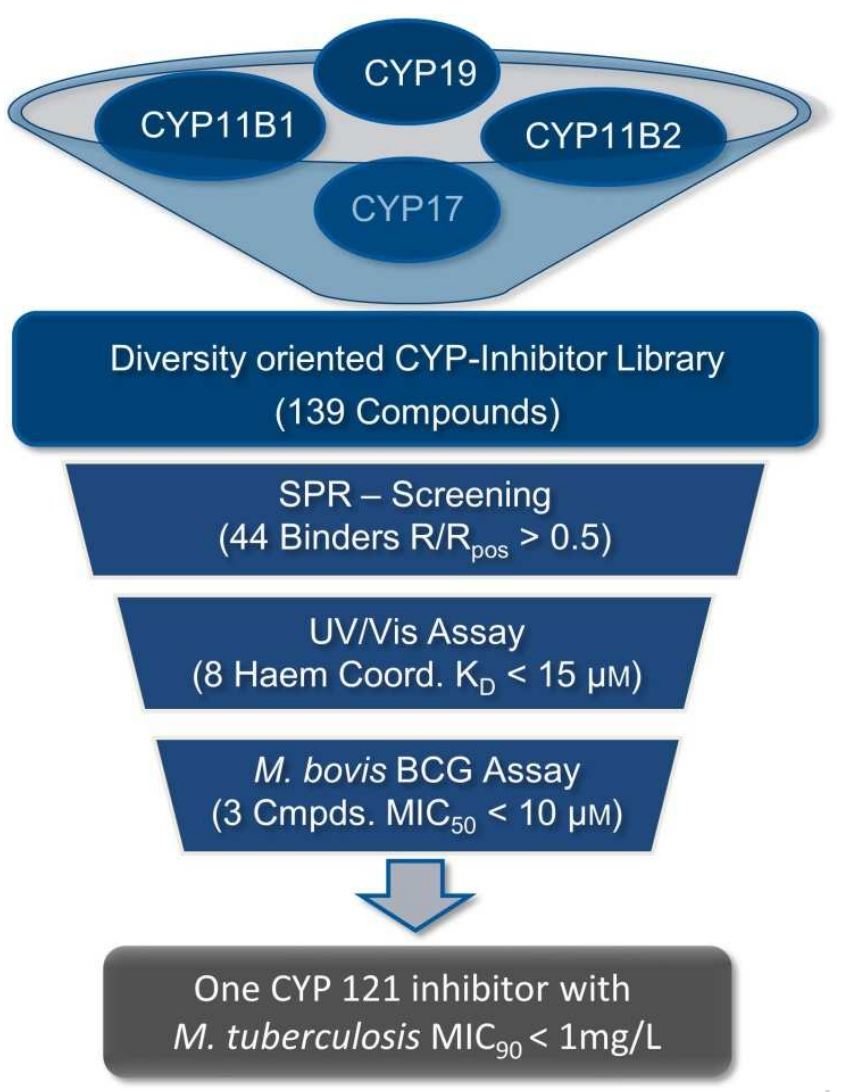

Scheme 1. Hit finding progress. The initial library (139 compounds) was built of inhibitors designed for inhibition of human CYP11B1/2, CYP17 and CYP19 with regard to structural diversity. A positive SPR screening hit was defined by the coefficient of its response divided by the response of the positive control (econazole) which had to be above $0.5\left(R / R_{\text {pos }}>0.5\right)$. This resulted in 44 positives. From this preselection, eight compounds coordinated iron-heme with a $\mathrm{K}_{\mathrm{D}}<15 \mu \mathrm{M}$. These compounds were tested against BCGT and three showed a $\mathrm{MIC}_{\mathrm{BCGT}}<10 \mu \mathrm{M}$. Finally, one compound was highly active on Mtb with a $\mathrm{MIC}_{\mathrm{Mtb}}<1 \mathrm{mg} / \mathrm{L}$

fragmentation with micromolar affinity and selectivity over other Mtb P450's without data concerning biological activity. ${ }^{[16]}$ Regarding compounds with cellular activity, it was shown that azole antifungals bind tightly to CYP121 and exhibit an in vitro and in vivo activity against Mtb. ${ }^{[17-22]}$ Furthermore, the binding to the enzyme was in good correlation with the antimycobacterial effect. $^{[8,22]}$ As the azole antifungals are active on Mtb cells and effective in mice infection models they display a valuable reference for antimycobacterial CYP inhibitors. ${ }^{[1-22]}$

The essential role of CYP121 for Mtb survival and our expertise in developing potent and selective human steroidogenic CYP enzyme inhibitors motivated us to identify novel CYP121 inhibitors with increased efficiency and improved properties compared to the azole antifungals. ${ }^{[23-27]}$

Potential antimycobacterial activity could provide further evidence of target validity, drugability and stimulate development of respective inhibitors towards new therapeutic agents bearing the potential to treat MDR and XDR Mtb infections. For these reasons, we established a screening strategy based on in vitro and cell-based assays (Scheme 1). By the use of a small highly diverse library composed of our CYP-inhibitors, we could identify a CYP121 inhibitor with increased antimycobacterial potency compared to positive control econazole. This compound possesses desirable physicochemical properties, low toxicity

\section{Classes of the CYP-Inhibitor Library}<smiles></smiles>

Class I (48 Cmpds)<smiles>[X]c1cc(CCC([R])c2cc3c4c(c2)CCN4C(=O)CC3)nn1C</smiles>

Class II (42 Cmpds)<smiles>[R][X]c1ccc(-c2ccc3c(c2)CCN3C([R])=O)cn1</smiles>

Class III (21 Cmpds)<smiles>[X]c1ccc(-c2ccccc2)cc1OCc1ccccc1</smiles>

Class IV (13 Cmpds)<smiles>[R]NC(=O)c1ccc([X])cc1</smiles>

\section{Class V (9 Cmpds)}

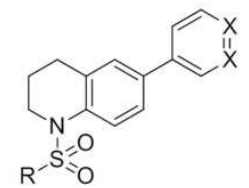

Class VI (6 Cmpds)

Figure 1. Classes of the library used for screening against CYP121 with their respective number of representatives stated in brackets. The structures represent the core scaffold of the compound where $R$ is a substituent, $X$ represent the position of either nitrogen or $\mathrm{CH}$, and [ ]n the alkyl chain length of $n$ methylene units

towards human cells and high antibacterial selectivity against Mtb, rendering it an appropriate candidate for further optimization.

\section{Results and Discussion}

Library generation. For hit discovery we selected 139 compounds from our in-house CYP-inhibitor library designed for inhibition of CYP17, CYP19, CYP11B1 and B2 (Supporting Information). The screening library is composed of six different scaffolds to ensure a broad structural diversity (Figure 1). Additionally, known pharmacological profiles, drug-likeness, and established synthetic routes of the compounds provide an ideal starting point for future optimization. As a reference compound we chose econazole which was shown to have the highest reported affinity to CYP121 (UV/Vis heme P450 binding assay) and the strongest inhibition of mycobacterial growth in the class of azole antifungals. ${ }^{[19,22]}$

Enzyme expression, characterization and initial SPR Screening. As starting point for SPR screening we expressed CYP121 in a heterologous host (E. coli K12 BL21) and purified the protein by ion affinity chromatography (IMAC). Notably, addition of $1 \%$ Triton-X-100 into the lysis buffer during purification increased the protein yield by about 10 -fold. ${ }^{[28]}$ The purity of the enzyme was determined by SDS-PAGE (Supp. Data, section 2, Figure S1). To ensure active protein conformation we conducted enzymatic in vitro activity tests. A first experiment to gain information about activity of P450 enzymes is the determination of CO-binding spectra. ${ }^{[29]} 50 \%$ of 


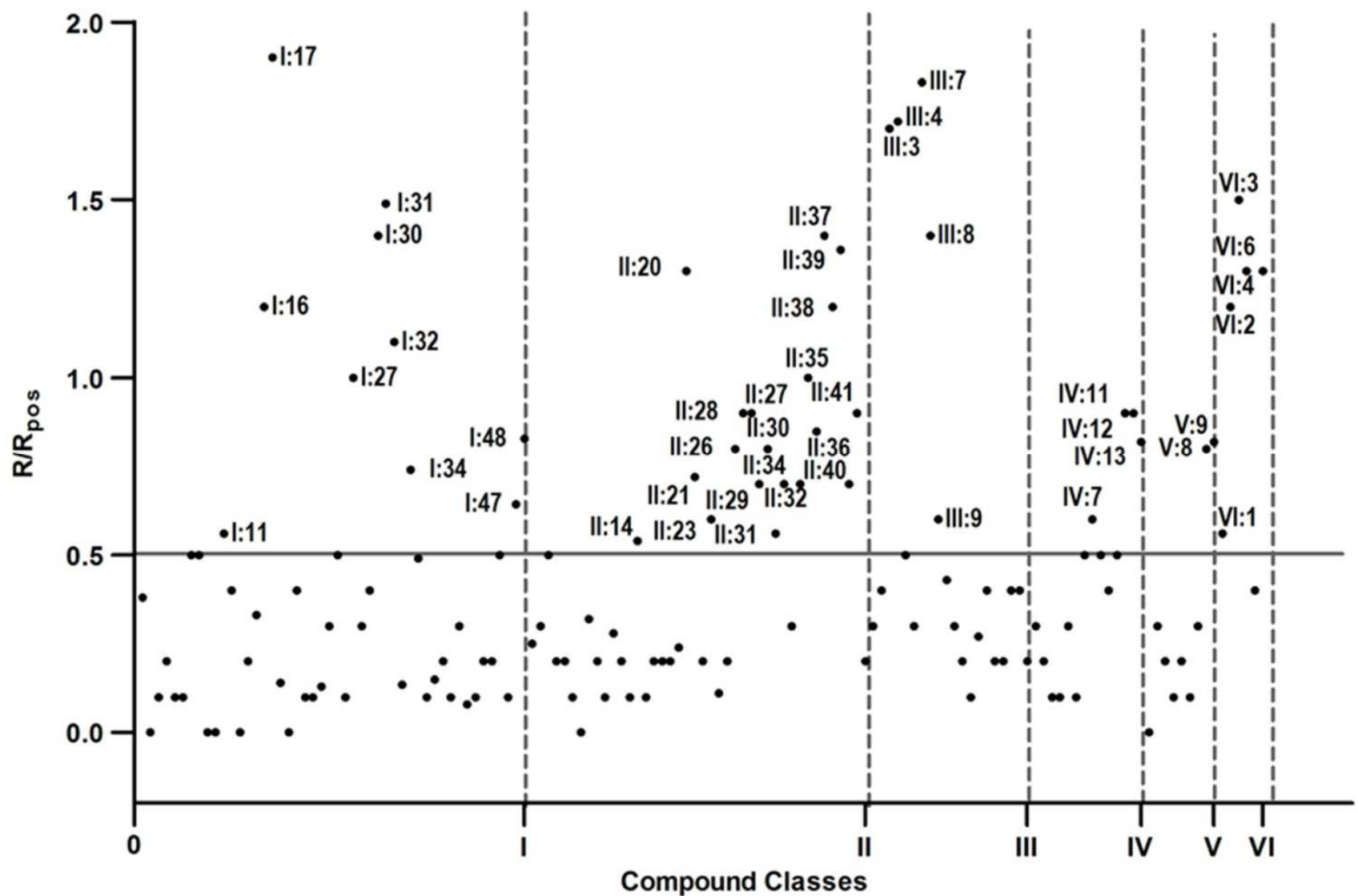

Figure 2. SPR screening results: compounds plotted versus their $R / R_{\text {pos }}$ values. Econazole $(100 \mu M)$ was used as a positive control and its $S P R$ response was set to $1\left(R_{\text {pos }}\right)$. The compounds were tested at a concentration of $100 \mu \mathrm{M}$ and their response $(R)$ was divided through the response of positive control $\left(R / R_{\text {pos }}\right)$. Hit compounds possess $\mathrm{R} / \mathrm{R}_{\text {pos }}$ values $>0.5$ (horizontal solid grey line). Vertical dashed lines separate the six classes.

the expressed enzyme showed the typical P450 band of CObound heme after dithionate reduction (Supp. Data, section 3, Figure S2 and S3). Using the same experimental conditions but replacing sodium dithionate, we were able to identify Etp1fd (516-618) as ferredoxin and Arh1_A18G as ferredoxin reductase two proteins of the fungus/fission yeast Schizosaccharomyces pombe ${ }^{[30,31]}$ as suitable heterologous electron transfer system for CYP121. Additionally, utilizing the latter system, we could show conversion of cYY to mycocyclosin proving enzymatic activity of CYP121 (Supp. Data, section 4, Figure S4 and S5).

Surface plasmon resonance spectroscopy (SPR) is a modern, yet well-established biophysical methodology allowing for the detection of binding events between an immobilized target (e.g. enzyme) and a solvated analyte. ${ }^{[32]}$ However, interactions detected by SPR can also occur outside the enzymes active site. Hence, this SPR-based primary screening filter was used to distinguish between binders and non-binders.

For SPR immobilization of the protein we used the biotinstreptavidin interaction. ${ }^{[33]}$ Prior to immobilization we conjugated a biotin tag to CYP121. To confirm applicability of the SPR method, we determined a response curve of econazole to the target protein (Supp. Data, section 5, Figure S6). ${ }^{[8]}$ The SPR signal of econazole, measured in response units (RU), was set to one $\left(R_{\text {pos }}\right)$. The binding event of library compounds $(R)$ was referenced to the positive control and declared as $R / R_{\text {pos. }}$. We defined $R / R_{\text {pos }}>0.5$ as the threshold for hits from SPR screening procedure. Using this approach, we identified 44 binders out of 139 compounds with representatives from all of the six classes (Figure 2). Notably, we found 17 compounds with higher responses than econazole (Supp. Data, section 6, Table S1).

Binding mode and affinity characterization via UV/Vis heme binding assay. The 44 SPR binders were investigated for their ability to interact with the iron(II)-heme by monitoring the shift of the characteristic absorbance band at $416 \mathrm{~nm}$ of CYP121 (Figure 3). ${ }^{[8,13]}$ In addition to the 44 SPR hits, we also took two weak SPR binders into consideration (I: 1 and $\left.\mathbf{I}: \mathbf{3 3}, \mathbf{R} / \mathbf{R}_{\text {pos }}<0.5\right)$ to conduct a retrospective evaluation of the reliability of our SPR screening. McLean et al. reported that econazole has a tightbinding profile to CYP121 with a $\mathrm{K}_{\mathrm{D}}=0.02 \mu \mathrm{M} .{ }^{[8]}$ However, we observed a $K_{D}$ of $3 \mu \mathrm{M}$. This discrepancy could be due to a difference in UV/Vis spectrometric devices used and, thus, limited sensitivity. To provide a higher throughput employing 96well plates, we were limited to a higher enzyme concentration which impairs measurement in lower nanomolar ranges. Compounds were initially tested at a concentration of $100 \mu \mathrm{M}$ to identify iron-heme interactions and distinguish between type I (water bridged iron-interaction) and type II (direct ironinteraction) binding. 30 compounds showed a type II shift while none showed type I binding behavior. The latter compounds appear in class I, II, III and IV indicating that the catalytic center 


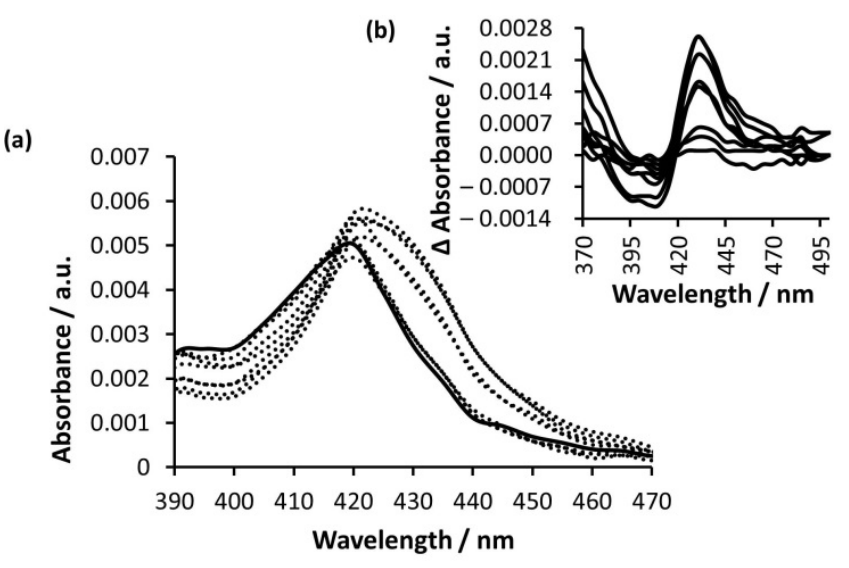

(c)

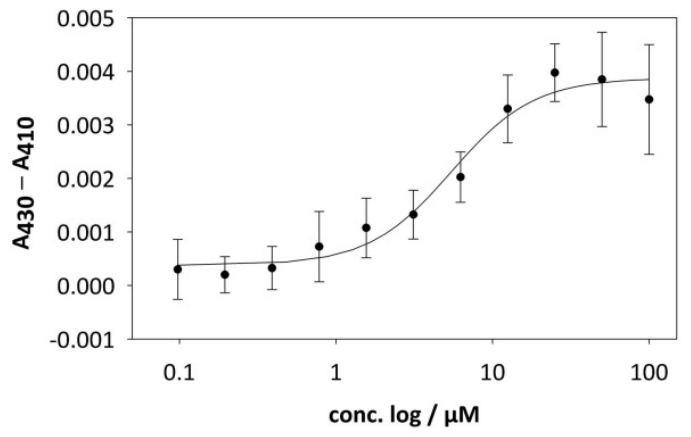

Figure 3. Binding of I:47 to CYP121 as determined from heme coordination assay: UV/Vis spectrum (a) and difference spectra (b) of the enzyme were recorded in the presence of I:47 $(100,50,25,12.5,6.25,3.13,1.56,0.78,0.39$, $0.20,0,10 \mu \mathrm{M}$; dotted lines) and in the absence of I:47 (solid line). (c): The $\mathrm{K}_{\mathrm{D}}$ value of I:47 was derived by non-linear fitting of the data using Equation 1 and the difference in absorption at 430 and $410 \mathrm{~nm}$. The error bars represent the standard deviation of three replicate measurements.

accepts imidazolyl- and pyridinyl-moieties for iron-heme coordination. I:1 and I:33 (weak SPR binders) did not coordinate the heme-iron which emphasizes the suitability of our SPR screening procedure. The identified type II binders were further investigated regarding their $\mathrm{K}_{\mathrm{D}}$. For eight binders an affinity better than $15 \mu \mathrm{M}$ was observed (Supp. Data, section 6, Table S1). Interestingly, this subset of compounds only arose from classes I and II. Pyridinyl (class II) as well as imidazolyl (class I) motifs were tolerated as heme coordinators while the imidazolyl ligands showed higher affinities (Supp. Data, section 6, Table S1). With regard to class I the highest affinity could be found for compounds decorated with hydrophobic and space-demanding moieties connected to the benzylimidazole substructure. This is also a structural trend in the class of antimycobacterial azoles (e.g. econazole, clotrimazole). ${ }^{[8]}$ The most affine binder I:16 showed three-fold improved $K_{D}$ compared to econazole $\left(K_{D}=\right.$ $3 \mu \mathrm{M}$ ) (Supp. Data, section 6, Table S1). Furthermore, two linearized, para-substituted biphenyl compounds of this class (I:47 and I:48) possessed a CYP121 affinity comparable to econazole. As mentioned before, molecules with linear biphenyl units bearing an $\mathrm{N}$-methylenbenzimidazoyl moiety instead of an unsubstituted benzylimidazolyl scaffold did not bind to the heme (I:33). Additionally, replacement of the interconnecting phenyl group within this class by pyridinyl resulted in inactive compounds (I:1). Moreover, the analysis of all regioisomers of benzylimidazol scaffolds substituted with phenyl revealed that the para- (I:32) and meta- (I:30) position lead to comparable affinities. A phenyl group at the ortho-position (I:15) impairs binding. The para-benzodioxine substituent of I:48 and the parabenzodioxole substituent of I:47 increase the affinity by about two-to threefold (Supp. Data, section 6 Table S1). However, compared to econazole our most active compounds showed similar (e.g.: I:47; $5 \mu \mathrm{M}$ and I:48; $5 \mu \mathrm{M}$ ) or slightly better $\mathrm{K}_{\mathrm{D}}$ (I:16; $1 \mu \mathrm{M})$ (Supp. Data, section 7, Figure S7).

MIC determination in BCGT and Mtb. For investigating cellular activity we focused on those compounds with a $K_{D}$ lower than $15 \mu \mathrm{M}$, but also added selected compounds showing low affinity to CYP121 as negative controls (Supp. Data, section 6, Table $\mathrm{S} 1)$. In this setting, econazole was used as described antimycobacterial reference compound. ${ }^{[34]}$ For initial screening on mycobacterial growth inhibition we used the bovine strain BCGT. The strain serves as a suitable substitute for Mtb as it carries a copy of CYP121 in its genome with an overall amino acid identity of $100 \%$ in comparison to its Mtb congener (Supp. Data, section 8, Figure S8). ${ }^{[35]}$ Regarding the more complex situation in the cellular context, the six identified classes have to be discussed separately. In case of subset III to VI, we could only detect weak growth inhibition ( $\mathrm{MIC}_{\mathrm{BCGT}}>10 \mathrm{mg} / \mathrm{L}$; Supp. Data, section 6, Table S1). In class II three compounds were found to have a $K_{D}$ value below $15 \mu \mathrm{M}$ but none of them had

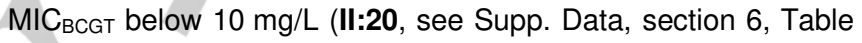
S1). For econazole, we observed a $\mathrm{MIC}_{\mathrm{BCGT}}=5.4 \mathrm{mg} / \mathrm{L}$ which is in good correlation to previous findings. ${ }^{[34]}$ Most active compounds were observed in class I (Supp. Data, section 9, Figure S9 and S10). The best heme-binder to CYP121 (I:16) with a three-fold increased affinity compared to econazole showed a MIC BCGT of $1.6 \mathrm{mg} / \mathrm{L}$. For I:47 and I:48 we could determine $\mathrm{MIC}_{\mathrm{BCGT}}=0.3 \mathrm{mg} / \mathrm{L}$ and $2 \mathrm{mg} / \mathrm{L}$ which renders I:47 to be the most potent antimycobacterial compound in this subset. The MIC tests of negative controls out of class I (I:1 and I:33) showed no significant growth inhibition. Within class I results of the MIC assay are in good correlation to the $K_{D}$ values on the target enzyme CYP121 (Table 1).

To test the potency of the most effective antimycobacterial compounds against the human pathogen Mtb, we used the MABA assay system. For $\mathrm{MIC}_{\mathrm{Mtb}}$ determination we chose the common laboratory strain $\mathrm{H}_{37} \mathrm{Rv}$. In several studies the $\mathrm{MIC}_{\mathrm{Mtb}}$ value of econazole was determined ranging from $0.12 \mathrm{mg} / \mathrm{L}$ to $8 \mathrm{mg} / \mathrm{L} .^{[8,20]}$ To facilitate comparability of the $\mathrm{MIC}_{\mathrm{Mtb}}$ values, we referenced them to results made in our assay system where a $\mathrm{MIC}_{\mathrm{Mtb}}$ for econazole of $4.2 \mathrm{mg} / \mathrm{L}$ was determined previously. ${ }^{[34]}$ The most effective compounds were I:47 with $\mathrm{MIC}_{\mathrm{Mtb}}=0.3 \mathrm{mg} / \mathrm{L}$ followed by I:16 $\left(\mathrm{MIC}_{\mathrm{Mtb}}=1.9 \mathrm{mg} / \mathrm{L}\right)$ and I:48 $\left(\mathrm{MIC}_{\mathrm{Mtb}}=3.5 \mathrm{mg} / \mathrm{L}\right.$, see Table 1). Notably, in terms of cellular efficiency metrics, I:47 has an $A E=0.39$ and hence, a higher $A E$ than econazole (0.24) and rifampicin (0.16) (Supp. Data, section 10, Table S2).

Toxicity on human cell lines. The azole antifungals are known to attenuate growth of several human cell lines. ${ }^{[36,37]}$ To compare cellular toxicity of econazole with our three most promising hits we used HEK293 cells in a MTT-based assay. ${ }^{[38]} 6.0 \mathrm{mg} / \mathrm{L}$ of econazole killed $50 \%$ of HEK 293 cell population after $48 \mathrm{~h}$. Notably, the toxicity of our most active antimycobacterial compounds was lower compared to the azole antifungal drug $\left(\mathrm{I}: 16 \mathrm{LD}_{50}=6.1 \mathrm{mg} / \mathrm{L} ; \mathrm{I}: 47 \mathrm{LD}_{50}=18.6 \mathrm{mg} / \mathrm{L} ; \mathrm{I}: 4822.3 \mathrm{mg} / \mathrm{L}\right)$. For comparability reasons, we calculated the toxicity factor for 
Table 1. Structures, relative SPR responses $\left(R / R_{\text {pos }}\right)$, binding affinities $\left(K_{D}\right)$ and antimycobacterial activities of econazole, most active hits $(I: 16$, I:47, I:48), examples for negatives (I:1, I:33) and for moderately active hits (I:15, I:30, I:32).

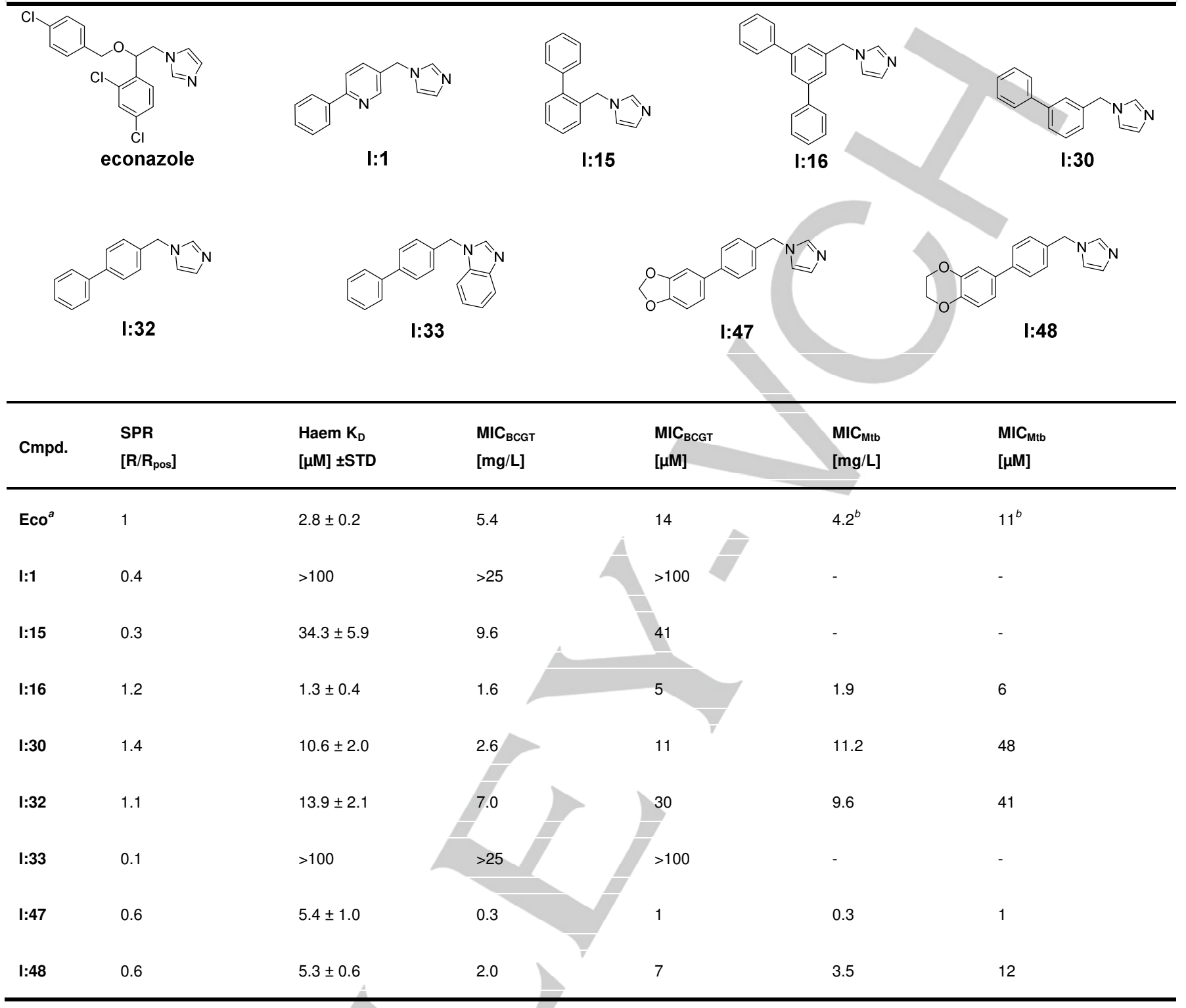

[a] Eco = econazole. [b] $\mathrm{MIC}_{\mathrm{Mtb}}$ determined previously. ${ }^{[34]}$

I:47 $\left(\mathrm{MIC}_{\mathrm{Mtb}} / \mathrm{LD}_{50}\right)$, which revealed a 44 -fold improvement compared to econazole (Table 2). One of the most prominent undesirable effects of azole antifungals is their hepatotoxicity observed in mice. ${ }^{[37,39]}$ For this reason, we also conducted toxicity experiments employing HepG2 cells. We could observe an approximately 2-fold increased toxicity for econazole $(3.1 \mathrm{mg} / \mathrm{L})$ and $\mathrm{I}: 16(3.9 \mathrm{mg} / \mathrm{L})$ compared to HEK293 cells. The $\mathrm{LD}_{50}$ of I:47 was $17.1 \mathrm{mg} / \mathrm{L}$ which is close to the toxicity seen in HEK cells. (vide supra, Supp. Data, section 11, Table S3).

In vitro and in cellulo mode of action studies. In addition to the binding constant, we determined inhibition of CYP121 enzymatic reaction by I:47. The enzyme catalyzes the formation of an intramolecular $\mathrm{C}-\mathrm{C}$ bond between the carbon atoms in ortho-position to the hydroxyl-group of the phenol-moiety of $\mathrm{cYY}$ resulting in the production of mycocyclosin. ${ }^{[10]}$ For assessing CYP121 activity we used an artificial redox-system from
Schizosaccharomyces pombe (ferredoxin Etp1fd (516-618) and ferredoxin reductase Arh1_A18G). ${ }^{[1]}$ This redox-system is known for its broad applicability as electron-donor for CYP enzymatic reactions but firstly described for CYP121 herein. Indeed, we could observe an inhibition of product formation confirming I:47 to be a potent inhibitor of mycocyclosin production by interference with CYP121 in vitro (Supp. Data section 4). To gather further evidence for target-based mycobacterial selectivity towards other bacteria, we assessed the activity of our compounds on growth of $E$. coli TolC as a representative for Gram-negative bacteria and $S$. aureus Newmann strain for Gram-positive. The results show no significant growth inhibition of I:47 and I:48 against the latter bacteria $\left(\mathrm{MIC}_{\mathrm{Mtb}}>100 \mu \mathrm{M}\right.$ or $\left.>25 \mathrm{mg} / \mathrm{L}\right)$. In contrast to econazole and I:16 that showed certain inhibitory effects for $E$. coli and S. aureus in higher concentrations (Supp. Data, section 12, Figure S11). 
Table 2. Comparison of human cellular toxicity and anti-Mtb effect.

\begin{tabular}{llll}
\hline Compound & $\begin{array}{l}\mathrm{MIC}_{\mathrm{Mtb}} \\
{[\mathrm{mg} / \mathrm{L}]}\end{array}$ & $\begin{array}{l}\mathrm{LD}_{50} \mathrm{HEK} \mathrm{293} \\
\text { cells }[\mathrm{mg} / \mathrm{L}]\end{array}$ & $\begin{array}{l}\text { Toxicity factor } \\
\mathrm{MIC}_{\mathrm{Mtb}} / \mathrm{LD}_{50}{ }^{a}\end{array}$ \\
\hline Eco & 4.2 & 6.0 & 1.4 \\
I:16 & 1.9 & 6.1 & 3.2 \\
I:47 & 0.3 & 18.6 & 62.0 \\
I:48 & 3.5 & 22.3 & 6.4 \\
\hline
\end{tabular}

[a] Toxicity factor $\left(\mathrm{MIC}_{\mathrm{Mtb}}\right.$ (Mtb) divided by $\mathrm{LD}_{50}$ (HEK293)) was used to enhance comparability of compounds with regard to their antimycobacterial effect.

Physicochemical and selectivity profile of 1:47. The aforementioned compounds were originally designed as inhibitors of human CYP17, CYP19 and CYP11B1/2 known to be involved in steroid biosynthesis. I:47 was initially synthesized as an inhibitor of CYP17. The compound showed only a low activity on CYP17 compared to other inhibitors with an $\mathrm{IC}_{50}=$ $3.1 \mu \mathrm{M}$. Additionally, only a $48 \%$ inhibition of aromatase at a concentration of $25 \mu \mathrm{M}$ was observed. ${ }^{[40]}$ Regarding physicochemical properties suitable for permeation through the cellular membranes, one has to differentiate between biological barriers of human and mycobacterial origin. For humans, a guidepost for appropriate physicochemical properties is the Lipinski's rule of five for oral bioavailability of drugs $(<5$ hydrogen bond donors, $\leq 10$ hydrogen bond acceptors, MW < $500 \mathrm{Da}, \log \mathrm{P} \leq 5) \cdot{ }^{[41]}$ Our frontrunner compound I:47 fulfils all four criteria ( 0 hydrogen bond donors, 3 hydrogen bond acceptors, $M W=278 \mathrm{Da}$, $\log P=3.1$ ) (Supp. Data, section 13). To the best of our knowledge, akin correlations for physicochemical properties with mycobacterial membrane passage were not set up, yet. Thus, a respective guide for compound development is still missing. ${ }^{[42]}$

Molecular modelling studies on the binding mode of I:47. As a type II binding profile was observed for I:47, we set up a constrained docking protocol to predict its binding mode to the heme center of CYP121. Docking to the active site of CYP121 was restricted by two essential pharmacophore features reflecting the direct interaction between the coordinated iron and I:47 (type II binding). The resulting docking poses were sorted by their predicted binding energies and the best scored docking pose was chosen for further studies (Figure 4). This modelling approach revealed new possibilities for further derivatization or rigidification. For instance, intramolecular linking of the methylene bridge at the imidazolyl unit with the ortho-position of phenyl using e.g. a five-membered ring should be tolerated by CYP121 and increase affinity through reduction of entropic penalties upon binding. Furthermore, the central hydrophobic aromatic moiety shows Van-der-Waals contacts to flanking hydrophobic amino acids Phe-168 and Met-62. Regarding steric factors, the ring could easily rotate in this position. This degree of rotatable freedom might be necessary to place the (a)

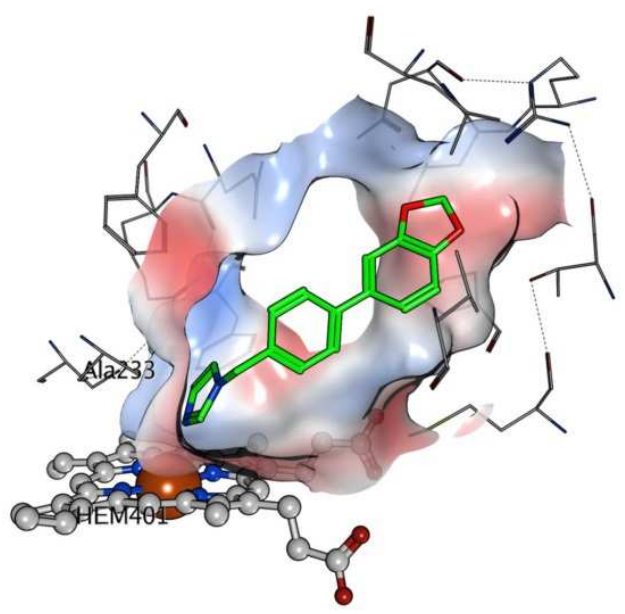

\section{(b)}

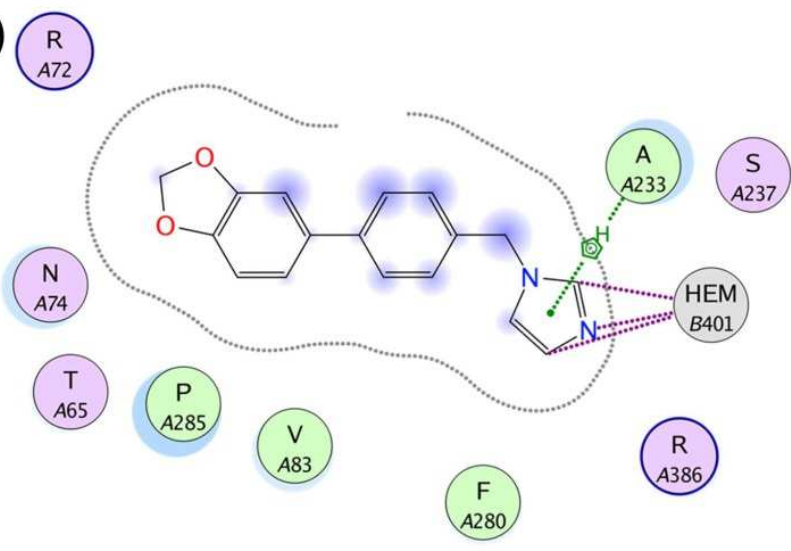

Figure 4. Molecular docking of I:47 against the prepared co-crystal structure of CYP121. Heme coordination was a prerequisite for the docking process which was achieve by placing a pharmacophore feature on the interacting metal and ligand position. Resulting docking poses were sorted by score (E_refine) and the highest scored pose is depicted as 3D model (a) and 2Dinteraction chart (b). I:47 shows close van der Waals contacts to surrounding amino acids but also possibilities for compound enlargement (b). The grey surface in panel (a) represents the van der Waals surface of the protein, which is also shown as dotted lines in panel (b).

aforementioned phenyl in a suitable position to grant access to a large flat subpocket (composed of Met-61, Asn-84 and the backbone of Asn-83) which could then be reached by substituents at its 2-postion. The 1,3-benzodioxole moiety was placed in a hydrophilic subpocket, formed by Arg-72, Asn-74 and Thr-65, which is in good accordance with the low lipophilicity of this motif $(\operatorname{cLogP}=0.27)$. Moreover, the 5 -position of 1,3 benzodioxole holds great potential for further enlargement of the molecule, as it directly points to another subpocket which is decorated with several hydrophobic amino acids, namely Leu-73, Phe-280, Leu-284 and the sidechain of Gln-385.

\section{Conclusions}

Despite the fact that CYP121 had been reported to be a potential target for the treatment of Mtb infections, not many inhibitors with cellular activity had been discovered. Herein we have presented a rational screening approach to address CYP121 by a small library focused on privileged scaffolds for CYP enzyme inhibition. The identified compounds could help to 
clarify the hitherto unknown role of CYP121 in Mtb metabolism and provide a good starting point for a drug optimization program.

Our search for new inhibitors of CYP121 started with an initial SPR screen of the aforementioned focused library. As the compounds were designed for P450 inhibition we observed a high number of binders (32\%). The identified compound classes differed highly with regard to their structures. Obviously, the large pocket of CYP121 (1350 $\left.\AA^{3}\right)$ which is necessary for the sterically demanding enzyme reaction can accept a large variety of differently shaped molecules. ${ }^{[8,10,43,44]}$ However, it has to be noted that the SPR method does not exclude compound attachment outside the enzymes active site.

For rational design approaches it is of high interest to clarify the binding mode and affinity of our hit compounds. A common method for P450 enzymes to address this issue is the heme coordination assay. ${ }^{[8]}$ All SPR-binders from classes III, IV, V and $\mathrm{VI}$ had only weak affinity to the heme-iron $\left(K_{D}>100 \mu \mathrm{M}\right)$. IV:13 is the only compound from this subset that could be titrated and gave a $K_{D}$ of $62 \mu \mathrm{M}$ (Supp. Data, section 6, Table 1). Therefore, we conclude that most of the compounds from these classes do not bind directly to heme but address another unknown site. This information could, however, be valuable for fragment-linking approaches at a later stage of drug development. For classes I and II we identified eight compounds with $K_{D}$ values below $15 \mu \mathrm{M}$. Notably, the best compounds of class II (II:20 and II:34) contained a space-demanding trityl-moiety. It was discussed for a crystal structure of CYP121 (PDB-ID: 1N40) that Arg-386 may restrict access of voluminous moieties to the iron-heme. ${ }^{[43]}$ Nevertheless, we observed that the enzyme can accommodate space-demanding molecules at the heme-site as shown by our UV/Vis experiments. Binders with the best affinity were found in class I. A comparison of compound structures and binding efficiencies within this class gave first evidence for properties needed to gain affinity towards CYP121. Imidazolyl head group linked by an methylene bridge to a hydrophobic core can be considered as an important basic structure for a good binding efficiency (I:16, I:47 and I:48). In case of the linearized compounds, an $N$ - methylenbenzimidazoyl head group (I:33), ortho-substituted biphenyl system (I:15), and an interconnecting pyridinyl (I:1) ring had unfavorable binding properties. In a hit optimization process these structural characteristics should be avoided. In contrast to this observation, a para-benzodioxine substituent (I:48) and a para-benzodioxole substituent (I:47) linked to the biphenyl system increases affinity. This might provide a possible position for further derivatization. Our docking study supports this result as this motif was predicted to be placed in a subpocket having a great potential for new interactions.

A straightforward approach for target validation is to correlate on-target potency and cellular activity. Although it has to be noted, that such a correlation can be flawed by the fact that compounds might also be inefficient due to e.g. poor membrane penetration. We hypothesized that class II might be a prime example for compounds that poorly permeate the membrane of mycobacteria and, thus, cannot reach their intracellular target. This could be an explanation for the lack of in cellulo activity although a moderate affinity to the target was measured.

Class $I$ is the most remarkable of the six classes showing reasonable affinity towards CYP121 and, more importantly, also high activity in cellulo against Mtb and BCGT. Furthermore, the on-target affinity of class I compounds directly correlates with their activity on mycobacteria which provides further evidence of a CYP121-dependent effect. In detail, on-target inactive compounds like I:1 and I:33 had no activity against BCGT, while moderate binders e.g. I:15, I:30 and I:32 had low antimycobacterial effects. Finally, compounds with highest affinity (I:16, I:47, I:48) were the most potent in the cellular setting. Especially, compounds I:16, I:47, and I:48 are even more effective on mycobacteria than the positive control, econazole, although no optimization has been undertaken, yet (Table 1). In terms of antibacterial efficiency (AE), I:47 is superior to econazole and the first-line drug rifampicin indicating an excellent optimization potential of this novel inhibitor class. Moreover, we could provide data that I:47 does not only bind to CYP121 but does also inhibit the enzyme reaction (Supp. Data, section 4). The correlation between MIC and $K_{D}$ bares minor inconsistences, which might be due to poor penetration through the mycobacterial cell wall of some compounds (see e.g. l:47 and econazole). A highly lipophilic molecule (e.g. econazole $\operatorname{cLog} \mathrm{P}=5.3$ vs. $\quad \mathrm{:}: 47 \quad \operatorname{cog} \mathrm{P}=3.1$ ) might be trapped in this lipophilic barrier containing mycolic acids and slowly or only partially released into the mycobacterial cytoplasm. This results in lower cellular activity than expected from on-target affinities. A second explanation for the differences in MIC and $\mathrm{K}_{\mathrm{D}}$, at least for econazole, is its promiscuous behavior in different growth inhibition assays. This suggests that there are additional targets for econazole. An explanation for the antibacterial activity of econazole against $E$. coli and $S$. aureus was already provided before. In these studies econazole was described as an inhibitor of Flavohemoglobin. ${ }^{[45,46]}$ Further possible target systems of azole antifungals within Mtb metabolism have also been described. ${ }^{[4-49]}$ However, evaluation of $\mathbf{I}: 47$ and $\mathbf{I}: 48$ leads to the conclusion that these novel structures are of improved selectivity towards Mtb with a good correlation of CYP121 affinity and antimycobacterial activity. Furthermore, the two compounds possess lower toxicity against human cells than determined for econazole. Although toxicity to hepatocytes was low, it is of high interest to clarify potential inhibition of metabolizing CYP enzymes (e.g. CYP3A4). These results further underline the target-based mycobacterial specificity of our compounds, at least in the subset of bacterial and human cells tested. Taken together the in vitro and cell-based studies conducted herein, CYP121 is most certainly the major target of $\mathrm{I}: \mathbf{4 7}$ and $\mathrm{I}: \mathbf{4 8}$.

In summary, we have reported a biophysical screening procedure employing a focused library of privileged scaffolds, which ultimately lead to the discovery of novel CYP121 inhibitors. From this process, I:47 turned out to be the most promising hit compound pairing convincing antimycobacterial activity and bacterial selectivity with a good toxicity profile. Furthermore, this compound exhibits a fragment-like molecular weight and preferable physiochemical properties that fulfil the Lipinski rules for oral bioavailability (Supp. Data, section 13). Thus, I:47 is an excellent starting point for rational structure-based drug discovery. Our in silico studies revealed several possible modifications to be investigated in future optimization steps. Additionally, the inhibitor might be a suitable candidate for an in vivo proof-of-concept study towards validation of CYP121 as a drug target.

\section{Experimental Section}


Bacterial strains and growth conditions: Bacterial strains used in this study were Mycobacterium bovis DSM-43990 (BCGT), Mycobacterium tuberculosis $\mathrm{H}_{37} \mathrm{Rv}$ (Mtb), Escherichia coli TolC acr A/B deficient, Staphyllococcus aureus (Newman strain) and E. coli K12 BL21. Mammalian cell lines for cytotoxicity evaluation were HEK293 (human embryonic kidney) and Hep2G (human liver carcinoma cells) cells. Mycobacteria were cultured in $7 \mathrm{H} 9 \mathrm{GC}-$ Tween $^{[50]}$ or Middlebrook $7 \mathrm{H} 9$ broth complemented with ADC Enrichment (Middlebrook). E. coli TolC and $S$. aureus tests were performed in lysogenic broth (LB) and LB plus ADC Enrichment.

Chemical synthesis and analytical characterization: Chemicals were purchased from commercial suppliers and used without further purification. Column flash chromatography was performed on silica gel $(40-63 \mu \mathrm{m})$, and reaction progress was monitored by TLC on TLC Silica Gel $60 \mathrm{~F}_{254}$ plates (Merck, Darmstadt, Germany). All moisture-sensitive reactions were performed under nitrogen atmosphere using anhydrous solvents. ${ }^{1} \mathrm{H}$ and ${ }^{13} \mathrm{C}$ NMR spectra were recorded on Bruker Fourier spectrometers $(300 \mathrm{MHz})$ at ambient temperature with the chemical shifts recorded as $\delta$ values in ppm units by reference to the hydrogenated residues of deuterated solvent as internal standard. Coupling constants (J) are given in Hertz $(\mathrm{Hz})$, and signal patterns are indicated as follows: $\mathrm{s}$, singlet; d, doublet; dd, doublet of doublets; $t$, triplet; $m$, multiplet, br, broad signal. The purity of the final compounds was $>95 \%$ measured by HPLC with UV detection at $254 \mathrm{~nm}$. The SpectraSystem LC system consisted of a pump, an autosampler, and a UV/Vis detector (ThermoFisher, Dreieich, Germany). Mass spectrometry was performed on an LC-coupled Surveyor MSQ electrospray mass spectrometer (ThermoFisher, Dreieich, Germany). The system was operated by the Xcalibur software. An RP C18 NUCLEODUR ec 100-5 125×3 mm $5 \mu \mathrm{m}$ column (Macherey-Nagel $\mathrm{GmbH}$, Düren, Germany) was used as the stationary phase. All solvents were HPLC grade. In a gradient run, the percentage of acetonitrile (containing $0.1 \%$ trifluoroacetic acid) was increased from an initial concentration of $0 \%$ at $0 \mathrm{~min}$ to $100 \%$ at $15 \mathrm{~min}$ and kept at $100 \%$ for $5 \mathrm{~min}$. The injection volume was $10 \mu \mathrm{L}$, and flow rate was set to $800 \mu \mathrm{L} / \mathrm{min}$. MS analysis was carried out at a spray voltage of $3800 \mathrm{~V}$, a source CID of $10 \mathrm{~V}$ and a capillary temperature of $350^{\circ} \mathrm{C}$. Spectra were acquired in positive mode from 100 to $1000 \mathrm{~m} / \mathrm{z}$. $c Y Y$ and mycocyclosin were synthesized as described. ${ }^{[11,51]}$ Experimental details on modification of CYY and mycocyclosin synthesis and analytical data can be found in the Supplementary Data (Supp. Data, section 4). The synthesis of library compounds has been described previously: class $\mathrm{I}^{[40,52-56]}$, class $\mathrm{II}^{[57,58]}$, class $1 \mathrm{II}^{[59]}$, class IV ${ }^{[60]}$, class $\mathrm{V}^{[61]}$, and class $\mathrm{VI}^{[62]}$

Protein expression, purification and biotinylation: E. coli K12 BL21 (DE3) cells were transformed with plasmid harboring cyp121 gene (pHAT2/cyp121). ${ }^{[13]}$

The previously described ${ }^{[28]}$ enzyme expression and purification method was slightly modified: $\mathrm{His}_{6}$-tagged CYP121 $\left(\mathrm{H}_{6}\right.$-CYP121) was expressed in $E$. coli $\mathrm{K} 12 \mathrm{BL} 21$ and purified using a single affinity chromatography step. Briefly, E. coli K12 BL21 cells containing the pHAT2/cyp121 were grown in terrific broth medium containing $100 \mu \mathrm{g} / \mathrm{mL}$ ampicillin at $37^{\circ} \mathrm{C}$ until an $\mathrm{OD}_{600}$ of approximately 0.8 units was reached, followed by induction with $0.5 \mathrm{mM}$ IPTG and $0.5 \mathrm{mM} \delta$-aminolevulinic acid for $36 \mathrm{~h}$ at $25^{\circ} \mathrm{C}$ and $200 \mathrm{rpm}$. The cells were harvested by centrifugation (5000 rpm, $10 \mathrm{~min}, 4^{\circ} \mathrm{C}$ ), and the cell pellet was resuspended in $100 \mathrm{~mL}$ of binding buffer containing $1 \%$ Triton- $\mathrm{X}-100(50 \mathrm{mM}$ tris- $\mathrm{HCl}, 300 \mathrm{mM}$ $\mathrm{NaCl}, 20 \mathrm{mM}$ imidazole, $10 \%$ glycerol, $\mathrm{pH}=7.2$ ) and lysed by sonication for a total process time of $2.5 \mathrm{~min}$. Cellular debris was removed by centrifugation $\left(18,500 \mathrm{rpm}, 40 \mathrm{~min}, 4^{\circ} \mathrm{C}\right)$, and the supernatant was filtered through a syringe filter $(0.2 \mu \mathrm{m})$. The clear lysate was immediately applied to a Ni-NTA affinity column, washed with binding buffer, and eluted with a one-step gradient of $500 \mathrm{mM}$ imidazole. The protein containing fractions were buffer-exchanged into storage buffer $(140 \mathrm{mM}$ $\mathrm{NaCl}, 10 \mathrm{mM} \mathrm{Na}_{2} \mathrm{HPO}_{4}, 2.7 \mathrm{mM} \mathrm{KCl}, 1.8 \mathrm{mM} \mathrm{KH}_{2} \mathrm{PO}_{4}$ and $10 \%$ glycerol $(\mathrm{v} / \mathrm{v}), \mathrm{pH}=7.2$ ), using a PD10 column (GE Healthcare, Little Chalfont, UK) and judged to be pure by SDS-PAGE analysis. Then protein was stored in aliquots at $-80^{\circ} \mathrm{C}$ in a final concentration of $50 \mu \mathrm{M}$. ${ }^{[28]}$
Before SPR streptavidin immobilization CYP121 was biotinylated. For biotinylation, Sulfo-NHS-LC-LC-Biotin (Thermo Science, Waltham, US) was dissolved in storage buffer $\left(140 \mathrm{mM} \mathrm{NaCl}, 10 \mathrm{mM} \mathrm{Na}_{2} \mathrm{HPO}_{4}, 2.7 \mathrm{mM}\right.$ $\mathrm{KCl}, 1.8 \mathrm{mM} \mathrm{KH}_{2} \mathrm{PO}_{4}$ and $10 \%$ glycerol (v/v)) with CYP121 in 1:1 molar ratio. The solution was incubated on ice for $2 \mathrm{~h}$ and mixed carefully every $30 \mathrm{~min}$. The biotinylated CYP121 was purified by size exclusion chromatography using the storage buffer and subsequently stored at $80^{\circ} \mathrm{C}$ at a final concentration of $10 \mu \mathrm{M} .{ }^{[63]}$

Spectroscopic characterization of enzyme activity: Recombinant CYP121 from Mycobacterium tuberculosis as well as ferredoxin Etp1fd (516-618) and ferredoxin reductase Arh1_A18G from the fission yeast Schizosaccharomyces pombe were expressed and purified as described previously. ${ }^{[30,31]}$

Functionality of CYP121 and electron transfer was assayed by the occurrence of the characteristic absorbance maximum at $\lambda \cong 450 \mathrm{~nm}$, related to the reduced, CO-bound heme complex. The assay was conducted following the method of Omura and Sato ${ }^{[29]}$ with slight modifications. CYP121 (2 $\mu \mathrm{M})$ was reduced through the addition of a few grains of sodium dithionite or incubation with NADPH $(100 \mu \mathrm{M})$, ferredoxin Etp1fd(516-618) $(40 \mu \mathrm{M})$, and Arh1_A18G ferredoxin reductase $(2 \mu \mathrm{M})$ and divided in two cuvettes to record a baseline. One of the samples was saturated with carbon monoxide for $60 \mathrm{~s}$ and difference spectra were recorded until the absorbance at $\lambda \cong 450 \mathrm{~nm}$ was constant.

SPR-Screening: SPR binding studies were performed using a Reichert SR7500DC instrument optical biosensor (Reichert Technologies, Munich, $\mathrm{DE})$ and SAD500m sensor chips obtained from XanTec Bioanalytics. CYP121 was immobilized on a SAD500m sensor chip at $12^{\circ} \mathrm{C}$ using standard biotin-streptavidin complexation. The surface of both channels was quenched by a $3 \mathrm{~min}$ injection of $0.003 \mathrm{mg} / \mathrm{mL}$ biotin. CYP121 was immobilized at densities between 5000 and $6000 \mathrm{RU}$ for binding studies.

UV/Vis heme P450 binding assay: Optical titration experiments were performed in 96 well plates (Greiner, Kremsmünster, AT; transparent round bottom). The data were recorded using Tecan infinite M200Pro Nano Quant (Tecan Groupe Ltd., Männedorf, DE). Absorbance of enzyme and enzyme-inhibitor complex was measured between 350 and $500 \mathrm{~nm}$ in $1 \mathrm{~nm}$ steps with 10 flashes. Compounds were titrated from DMSO stock solutions maintaining a final DMSO concentration of $1 \%$. CYP121 was used in a concentration of $0.25 \mu \mathrm{M}$. Data were plotted as optical shift versus ligand concentration. Equation 1 (Eq. 1) was used for non-linear regression of the resulting dose-response curves employing the Levenberg-Marquardt algorithm of Sigma Plot 12 (Systat Software $\mathrm{GmbH}$, Erkrath, DE).

$$
f=y_{\min }+\frac{y_{\max }-y_{\min }}{1+\left(\frac{x}{K_{D}}\right)^{-s l o p e}}
$$

Equation 1. $f$ is the observed difference in absorbance at wavelengths $410 \mathrm{~nm}$ and $430 \mathrm{~nm}$ within the difference spectrum (see Figure 3) at ligand concentration $x$. This difference spectrum is obtained by subtracting the pure heme absorption spectrum from those with ligand present. $y_{\max }$ refers to the absorbance change at ligand saturation, $y_{\min }$ is the extrapolated minimal difference in absorbance; $K_{D}$ refers to the dissociation constant of the CYP121 ligand complex. ${ }^{[22]}$

Determination of $\mathrm{BCGT}$ MIC $\mathrm{BCGT}_{\mathrm{BC}}$ by $\mathrm{OD}_{600}$ assay: $\mathrm{A}$ pre-culture of BCGT was grown in $7 \mathrm{H} 9$ medium supplemented with ADC Enrichment for 10 days. The assay was performed in 48 well plates (Greiner, Kremsmünster, AT). Prior to culture addition, compounds were serially diluted in DMSO to fit a final DMSO concentration of $1 \%$. For compound susceptibility the pre-culture was diluted 1:100 with fresh medium $(7 \mathrm{H} 9+$ ADC enrichment). After $168 \mathrm{~h}$ of incubation at $37{ }^{\circ} \mathrm{C}$ and $80 \%$ air moisture, bacterial growth was measured by determination of $\mathrm{OD}_{600}$. Absorption data was recorded on a Polarstar Omega Multidetection Plate Reader (BMG LABTECH, Ortenberg, DE). Graphs were plotted with 
GraphPad Prism using OneSite Log $\mathrm{IC}_{50}$ model provided by the software. MIC $_{\mathrm{BCGT}}$ was defined as the concentration at which 50 percent of growth was detected in accordance with previous methods used. ${ }^{[34]}$

In analogy to ligand efficiency, which relates activity of compounds to their number of heavy atoms, a new metric has been introduced: antibacterial efficiency (AE). ${ }^{[6,65]}$ This coefficient was developed for better comparability of antimicrobial compounds differing in molecular weight (Eq.2)

$$
A E=-\ln \left(\frac{M I C}{N H A}\right)
$$

Equation 2. $A E$ refers to the antibacterial efficiency, MIC is the minimal inhibitory concentration, and NHA equals the number of heavy atoms in a given compound.

Cyp121 in vitro enzyme inhibition assay: The enzyme inhibition assay was performed in $200 \mu \mathrm{L}$ PBS buffer $\mathrm{pH}$ 7.2. Compounds were used in a concentration of $100 \mu \mathrm{M}$ and incubated with $1 \mu \mathrm{M}$ CYP121 for 30 minutes at $30{ }^{\circ} \mathrm{C}$. The final DMSO concentration did not exceed $2 \%$. After incubation the electron transfer system Arh1 A18G $(5 \mu \mathrm{M})$, Etp1fd $(15 \mu \mathrm{M})$ and $\mathrm{NADPH}+\mathrm{H}^{+}(200 \mu \mathrm{M})$ was added. The reaction was started with the addition of $\mathrm{cYY}(50 \mu \mathrm{M})$ and stopped after $30 \mathrm{~min}$ by addition of $200 \mu \mathrm{l}$ methanol with internal standard estrone $(1 \mu \mathrm{M}$ final concentration, addition included)

The characterization of CYP121 activity was conducted by a UHPLCMS/MS analysis carried out on a TSQ Quantum Access Max mass spectrometer equipped with an HESI-II source and a triple quadrupole mass detector (Thermo Scientific, Dreieich, Germany). Compounds were

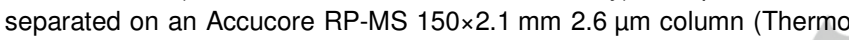
Fisher, Waltham, US) by a methanol/water gradient (from $1.4 \mathrm{~min}$ $3.5 \mathrm{~min} 50 \%$ methanol to $3.5 \mathrm{~min}-5.0 \mathrm{~min} 90 \%$ methanol) with a flow of $550 \mu \mathrm{L} / \mathrm{min}$. Compounds were ionized in negative mode by electrospray ionization. Ionization was assisted by a post-column addition of $2 \mathrm{mM}$ ammonia in methanol with an automated syringe at $1.25 \mu \mathrm{L} / \mathrm{min}$. Monitored ions were (mother ion [m/z], product ion $[\mathrm{m} / \mathrm{z}]$, scan time $[\mathrm{s}]$, scan width $[\mathrm{m} / \mathrm{z}]$, collision energy $[\mathrm{V}]$, tube lens offset $[\mathrm{V}]$, polarity): mycocyclosin: $323.101,111.100,0.3,0.7,28$, negative; CYY: 325.129 , 113.043, 0.3, 0.7. 29, negative; internal standard (estrone): 269.153, $145.035,0.3,0.7,42$, negative. Samples were injected in a volume of 25 $\mu \mathrm{L}$. Xcalibur software was used for data acquisition. For quantification, the ratios of the area under the curve of the educt and the product were used.

Determination $\mathbf{M I C}_{\mathrm{Mtb}}$ using MABA: The assay for determination of minimal inhibition concentration against Mtb was performed as previously described. ${ }^{[50]}$

$\mathrm{MIC}_{\mathrm{Eco}}$ E. coli TolC and $\mathrm{MIC}_{\mathrm{Sa}}$ S.aureus Newman: $\mathrm{MIC}_{\mathrm{Eco}} / \mathrm{MIC}_{\mathrm{Sa}}$ values were performed for econazole, I:16, I:47, I:48 in E. coli TolC and $S$. aureus Newman. A start $\mathrm{OD}_{600}$ of 0.03 was used in a total volume of $200 \mathrm{~mL}$ in lysogeny broth (LB) + ACD enrichment containing the compounds predissolved in DMSO. Final compound concentrations were prepared from serial dilutions ranging from 1.56 to $100 \mu \mathrm{M}$ in duplicates. The maximal DMSO concentration in the experiment was $1 \%$. The recorded $\mathrm{OD}_{600}$ values were determined after addition of the compounds and again after incubation for $18 \mathrm{~h}$ at $37^{\circ} \mathrm{C}$ and $50 \mathrm{rpm}$ in a 96-well plate (Sarstedt, Nümbrecht, Germany) using a FLUOStar Omega (BMG Labtech, Ortenberg, Germany). Given $\mathrm{MIC}_{\mathrm{E}_{\mathrm{co}}} / \mathrm{MIC}_{\mathrm{Sa}}$ values are means of two independent experiments (two different clones) and are defined as concentrations at which no bacterial growth was detectable.

Human cytotoxicity assay: HEK 293 cells $\left(2 \times 10^{5}\right.$ cells per well) were seeded in 24-well, flat-bottomed plates (Greiner Bioscience, Kremsmünster, AT). Culturing of cells, incubations and OD measurements were performed as described previously ${ }^{[38]}$ with minor modifications. $24 \mathrm{~h}$ after seeding of the cells the incubation was started by the addition of the compounds from DMSO stock solutions to a final DMSO concentration of $1 \%$. The living cell mass was determined $48 \mathrm{~h}$ after addition of the compounds and was followed by the calculation of $\mathrm{LD}_{50}$ values. The calculation of the $\mathrm{LC}_{50}$ values was performed by plotting the percent inhibition vs. the concentration of inhibitor on a semilogarithmic plot. From this, the molar concentration causing 50\% reduction of the living cell mass was calculated. At least three independent experiments were performed for each compound.

In silico binding mode of I:47: In silico studies were performed with the X-ray co-crystal structure of a type II inhibitor and CYP121 (PDB-ID: 4G44) using MOE software package (Chemical Computing Group). ${ }^{[66]}$ Prior to modelling, a pharmacophore model was created, placing a feature for an interacting metal on the haem iron (ML2, $R=1$ ) and a second feature for a metal ligand $(M L, R=1)$ on the iron-coordinating nitrogen of the co-crystalized ligand. Both features were set to be essential and constrained (Atoms/Projections). Before energy minimization with $\operatorname{LigX}$ the solvent and the ligand was deleted from the structure. For LigX, an AMBER10:EHT forcefield with the default parameters were used but the solvation model was changed to R-Field as recommended by the manufacturer. For docking experiments the following parameters were used: Protocols = induced fit, Receptor = Receptor+Solvent, Site $=$ Selected Atoms (these consisted of the haem and the surrounding amino acids in $4.5 \AA$ proximity), Pharmacophore = File (as described above), Ligand = MDB File (Database file with I:47, energy minimized with MMFF94x), Placement = Pharmacophore, Rescoring 1 = London dG, Refinement = Forcefield, Rescoring 2 = GBVI/WSA dG. 30 poses were retained within the placement and refinement step. The resulting poses were sorted by their $E \_$refine score and the first (best) pose was selected for further evaluation.

Physicochemical properties: Physicochemical properties were calculated using ACD/Percepta version 2012 (Build 2203, 29 jan. 2013), ACD/Labs.

\section{Acknowledgements}

Many thanks go to Jeannine Jung, Mellissa Meng and Phil Servatius for their experimental support. We also want to thank Prof. Munro (University of Manchester) for kindly providing us the plasmid harboring cyp121 gene (pHAT2/cyp121) and Prof. Bernhardt (Saarland University) for the kind gift of the purified ferredoxin Etp1fd(516-618) and ferredoxin reductase Arh1_A18G.

Keywords: ant-infectives • biophysics • inhibitors • Mycobacterium tuberculosis $\cdot$ screening

\section{References:}

[1] WHO Global tuberculosis report, 2014, DOI 10.1007/s10393-0140940-0.

[2] Z. F. Udwadia Amale, R.A., Ajbani, K.K., Rodrigues, C., Clin. Infect. Dis. 2012, 54, 579-581.

[3] A. A. Velayati, M. R. Masjedi, P. Farnia, P. Tabarsi, J. Ghanavi, A. H ZiaZarifi, S. E. Hoffner, Chest 2009, 136, 420-425.

[4] L. E. Connolly, P. H. Edelstein, L. Ramakrishnan, PLoS Med. 2007 4, 435-442.

[5] S. T. Cole, R. Brosch, J. Parkhill, T. Garnier, C. Churcher, D. Harris, S. V. Gordon, K. Eiglmeier, S. Gas, C. E. Barry, et al., Nature 1998, 393, 537-544.

[6] K. Duncan, Curr. Pharm. Des. 2004, 10, 3185-3194. 
K. J. McLean, D. Clift, D. G. Lewis, M. Sabri, P. R. Balding, M. J. Sutcliffe, D. Leys, A. W. Munro, Trends Microbiol. 2006, 14, 220228.

K. J. McLean, P. Carroll, D. G. Lewis, A. J. Dunford, H. E. Seward, R. Neeli, M. R. Cheesman, L. Marsollier, P. Douglas, W. E. Smith, et al., J. Biol. Chem. 2008, 283, 33406-33416. A. G. Tsolaki, A. E. Hirsh, K. Deriemer, J. A. Enciso, M. Z. Wong, M. Hannan, Y. L. G. De Salmoniere, K. Aman, M. Kato-maeda, P. M. Small, PNAS 2004, 101, 4865-4870.

[10] P. Belin, M. H. Le Du, A. Fielding, O. Lequin, M. Jacquet, J.-B. Charbonnier, A. Lecoq, R. Thai, M. Courcon, C. d. Masson, et al., Proc. Natl. Acad. Sci. 2009, 106, 7426-7431.

[11] M. Fonvielle, M.-H. Le Du, O. Lequin, A. Lecoq, R. Thai, S. Dubois, G. Grach, M. Gondry, P. Belin, J. Biol. Chem. 2013, 288, 1734717359.

[12] M. B. Martins, I. Carvalho, Tetrahedron 2007, 63, 9923-9932.

[13] S. A. Hudson, K. J. McLean, S. Surade, Y. Q. Yang, D. Leys, A. Ciulli, A. W. Munro, C. Abell, Angew. Chemie - Int. Ed. 2012, 51, 9311-9316.

[14] M. E. Kavanagh, A. G. Coyne, K. J. McLean, G. G. James, C. W. Levy, L. B. Marino, L. P. S. De Carvalho, D. S. H. Chan, S. A. Hudson, S. Surade, et al., J. Med. Chem. 2016, 59, 3272-3302. P. Belin, A. Leqoc, M.-H. Beaurepaire Ledu, M. Gondry, J.-L. Pernodet, Patent EP2088143A1, 2009.

[16] M. E. Kavanagh, J. L. Gray, S. H. Gilbert, A. G. Coyne, K. J. McLean, H. J. Davis, A. W. Munro, C. Abell, ChemMedChem 2016, 11, 1924-1935

[17] Z. Ahmad, S. Sharma, G. K. Khuller, P. Singh, J. Faujdar, V. M. Katoch, Int. J. Antimicrob. Agents 2006, 28, 543-544.

[18] Z. Ahmad, S. Sharma, G. K. Khuller, FEMS Microbiol. Lett. 2006, 261, 181-186.

[19] Z. Ahmad, S. Sharma, G. K. Khuller, FEMS Microbiol. Lett. 2006, 258, 200-203.

[20] Z. Ahmad, S. Sharma, G. K. Khuller, FEMS Microbiol. Lett. 2005, 251, 19-22.

[21] S. T. Byrne, S. M. Denkin, P. Gu, E. Nuermberger, Y. Zhang, J. Med. Microbiol. 2007, 56, 1047-1051.

[22] K. J. McLean, K. R. Marshall, A. Richmond, I. S. Hunter, K. Fowler, T. Kieser, S. S. Gurcha, G. S. Besra, A. W. Munro, Microbiology 2002, 148, 2937-2949

[23] M.-P. Leze, M. Le Borgne, P. Pinson, A. Palusczak, M. Duflos, G. Le Baut, R. W. Hartmann, Bioorg. Med. Chem. Lett. 2006, 16, 1134-1137.

[24] H. Bayer, C. Batzl, R. W. Hartmann, A. Mannschreckt, J. Med. Chem. 1991, 34, 2685-2691.

[25] F. Leroux, T. U. Hutschenreuter, C. Charriere, R. Scopelliti, R. W. Hartmann, Helv. Chim. Acta 2003, 86, 2671-2686.

[26] M. Voets, I. Antes, C. Scherer, U. Mu, K. Biemel, S. Marchaisoberwinkler, J. Med. Chem. 2006, 49, 2222-2231.

[27] S. Lucas, R. Heim, C. Ries, K. E. Schewe, B. Birk, R. W. Hartmann, J. Med. Chem. 2008, 51, 8077-8087.

[28] K. J. Mclean, M. R. Cheesman, S. L. Rivers, A. Richmond, D. Leys, S. K. Chapman, G. A. Reid, N. C. Price, S. M. Kelly, J. Clarkson, et al., J. Inorg. Biochem. 2002, 91, 527-541.

[29] T. Omura, R. Sato, J. Biol. Chem. 1964, 239, 2379-2385.

[30] K. M. Ewen, B. Schiffler, H. Uhlmann-schiffler, R. Bernhardt, F. Hannemann, FEMS Yeast Res. 2008, 8, 432-441.
[31] J. J. Müller, F. Hannemann, B. Schif, K. M. Ewen, R. Kappl, U. Heinemann, R. Bernhardt, J. Inorg. Biochem. 2011, 105, 957-965.

[32] J. Homola, Anal. Bioanal. Chem. 2003, 377, 528-539.

[33] H. Morgan, D. M. Taylor, Biosens. Bioelectron. 1992, 7, 405-410.

[34] S. G. Franzblau, M. A. Degroote, S. H. Cho, K. Andries, E. Nuermberger, I. M. Orme, K. Mdluli, I. Angulo-Barturen, T. Dick, V. Dartois, et al., Tuberculosis 2012, 92, 453-488.

[35] M. Altaf, C. H. Miller, D. S. Bellows, R. O'Toole, Tuberculosis 2010, 90, 333-337.

[36] I. Benko, F. Hernadi, A. Megyeri, A. Kiss, G. Somogyi, Z. Tegyey, F. Kraicsovits, P. Kovacs, J. Antimicrob. Chemother. 1999, 43, 675681.

[37] H. M. Korashy, A. Shayeganpour, D. R. Brocks, A. O. S. El-Kadi, Toxicol. Sci. 2007, 97, 32-43.

[38] J. Haupenthal, C. Baehr, S. Zeuzem, A. Piiper, Int. J. Cancer 2007, 121, 206-210.

[39] C. Liu, C. Lin, C. Lin, Y. Lin, C. Chen, C. Lin, S. Lin, Toxicol. 196 2004, 196, 87-93.

[40] B. G. Wachall, M. Hector, Y. Zhuang, R. W. Hartmann, Bioorganic Med. Chem. 1999, 7, 1913-1924.

[41] C. A. Lipinski, F. Lombardo, B. W. Dominy, P. J. Feeney, Adv. Drug Deliv. Rev. 2001, 46, 3-26.

[42] A. Koul, E. Arnoult, N. Lounis, J. Guillemont, K. Andries, Nature 2011, 469, 483-490.

[43] D. Leys, C. G. Mowat, K. J. McLean, A. Richmond, S. K. Chapman, M. D. Walkinshaw, A. W. Munro, J. Biol. Chem. 2003, 278, 51415147.

[44] C. Tanford, Science (80-. ). 1881, 200, 1012-1018.

[45] L. S. Nobre, S. Todorovic, A. F. N. Tavares, E. Oldfield, P. Hildebrandt, M. Teixeira, L. M. Saraiva, J. Bacteriol. 2010, 192, 1527-1533.

[46] R. A. Helmick, A. E. Fletcher, A. M. Gardner, C. R. Gessner, A. N. Hvitved, M. C. Gustin, P. R. Gardner, Antimicrob. Agents Chemother. 2005, 49, 1837-1843. H. M. Guardiola-Diaz, L. Foster, D. Mushrush, A. D. N. Vaz, Biochem. Pharmacol. 2001, 61, 1463-1470.

[48] H. I. M. Boshoff, T. G. Myers, B. R. Copp, M. R. Mcneil, M. A. Wilson, C. E. Barry, J. Biol. Chem. 2004, 279, 40174-40184.

[49] A. Milano, M. R. Pasca, R. Provvedi, A. P. Lucarelli, G. Manina, A. Luisa de Jesus Lopes Ribeiro, R. Manganelli, G. Riccardi, Tuberculosis 2009, 89, 84-90.

[50] L. A. Collins, Franzblau, Scott G., Antimicrob. Agents Chemother. 1997, 41, 1004-1009.

[51] J. R. Cochrane, J. M. White, U. Wille, C. A. Hutton, Org. Lett. 2012, 14, 2402-2405.

[52] U. E. Hille, C. Zimmer, C. A. Vock, R. W. Hartmann, ACS Med. Chem. Lett. 2011, 2, 2-6.

[53] C. Jagusch, M. Negri, U. E. Hille, Q. Hu, M. Bartels, K. JahnHoffmann, M. A. E. P. B. Mendieta, B. Rodenwaldt, U. Müler-Vieira, D. Schmidt, et al., Bioorganic Med. Chem. 2008, 16, 1992-2010.

[54] M. A. E. Pinto-Bazurco Mendieta, M. Negri, Q. Hu, U. E. Hille, C. Jagusch, K. Jahn-Hoffmann, U. Müller-Vieira, D. Schmidt, T. Lauterbach, R. W. Hartmann, Arch. Pharm. (Weinheim). 2008, 341 , 547-609.

[55] U. E. Hille, Q. Hu, C. Vock, M. Negri, M. Bartels, U. Müller-Vieira, T. Lauterbach, R. W. Hartmann, Eur. J. Med. Chem. 2009, 44, 27652775 . 